\title{
Does Ethnicity Moderate the Longitudinal Change in Adolescent Educational Expectations for University Study between ages 14-16? Understanding Differences among White, Indian, Pakistani, Bangladeshi and Black Caribbean Pupils in England
}

\begin{abstract}
By Michael Tzanakis ${ }^{*}$
Previous research has established that adolescent educational expectations for university study differ widely across UK ethnic minorities. This quantitative study explores change in expectations over time and across UK ethnic groups in a psychometric framework using cohort panel data from waves 1-3 of the Longitudinal Study of Young People in England (LSYPE). An autoregressive longitudinal latent variable structural equation model addresses the above research questions and enables direct tests of the assumptions of invariance, stationarity and equilibrium typically only assumed to hold in similar multi-group comparisons. Results show that pupils' educational expectations change significantly differently across ages 14-16 in the five ethnic groups reflecting moderation by maternal ethnicity. Expectations at age 14 exert important direct and indirect effects on expectations at age 16 via expectations at age 15. There is a general fall in expectations at age 15. Cross-group differences in latent means and intercepts suggest that in contrast to their white peers, minority pupils recover from this fall at age 16.
\end{abstract}

Keywords: adolescent educational expectations, ethnicity, longitudinal modelling, structural equation modelling

Introduction:

Adolescent Educational Aspirations, Expectations and Ethnicity

Educational aspirations and expectations are related but distinct concepts (Quaglia \& Cobb, 1996). Aspirations are argued to describe unrealistic or idealistic perceptions of future education or occupation (Goyette, 2008) during a natural developmental stage (Gottfredson, 1996). Expectations, on the other hand, are realistic assessments or predictions of future attainments, job category (Woelfel \& Haller, 1971) and available resources (Thompson, Alexander \& Entwisle, 1988). This analysis is concerned with young people's reported probability estimates for applying to university after year 11 and for being accepted if they applied. Pupils' responses reflect therefore reality-based expectations rather than idealistic aspirations about post-16 university study. Accordingly, the term expectations is used in this study.

\footnotetext{
* Department of Quantitative Social Science, Institute of Education, University of London, UK.
} 
It is well established that young people from poor backgrounds tend to have lower educational expectations and performances than their better-off peers (Sewell, Hauser \& Wolf, 1980). More recent evidence has generally confirmed this association (Jerrim, 2011). UK ethnic minority groups vary in their socio-economic status, but most are relatively disadvantaged compared to whites (the main exception to this is the Indians). So, one might expect minority ethnic children to have lower educational expectations than whites, and to make less progress in school. Yet precisely the opposite is the case. This creates the paradox of high expectations among less advantaged ethnic minority youth in the UK.

Previous research has studied the association of ethnicity and adolescent educational expectations and aspirations (Cooper, 2009; Strand, 2014; Strand \& Winston, 2008; for a review see, Tzanakis, 2014). However, the role of ethnicity in forming expectations is complex (Rutter \& Tienda, 2005). Rather than functioning as a simple exogenous predictor, ethnicity may function as a moderator e.g., a variable that impacts on the way a predictor affects an outcome (Hayes, 2013; Jose, 2013). Further, recent research has shown that ethnicity moderates not only the way parental social position affects adolescent expectations longitudinally, but also the ways this influence is mediated via a number of home and school-related factors (Tzanakis, 2014). Typically however, previous research on educational expectations has not tested this moderation hypothesis systematically. When this is attempted, the statistical framework adopted (typically, OLS multiple or logistic regression) did not allow high precision or power to detect a moderation effect (see for example, Lee, Hill \& Hawkins, 2012). Nor has the hypothesis that ethnicity moderates the longitudinal change in adolescent expectations received systematic attention.

\section{Longitudinal Change in Adolescent Expectations}

Recent quantitative research in the UK has focused on the longitudinal change in adolescent educational expectations to apply to university. Based on the Longitudinal Study of Young People in England (LSYPE) waves 1 to 7, Anders and Micklewright (2013) concluded that expectations to apply to university "hardened" through the teenage years, leaning towards the "very likely" or the "not very likely" categories. Expectations started lower and fell faster for those teenagers from disadvantaged backgrounds, or those who left full-time education (FTE) at age 16. High expectations persisted for those who remained in FTE and did A-levels. Fumagalli (2012) used the same data and studied change in the expectation to apply to university over the transition between ages 14 to 15 (years 9 to 10) depending on the probability of being admitted if they applied. The study showed that teenage expectations evolved the most during the transition between age 14 to 15 (years 9 to 10) as a consequence of new information received after KS3 performance tests. 


\section{Studying Educational Expectations in a Psychometric Framework}

None above studies focused on ethnic minority groups per se in the UK. Therefore, possible cross-group differences in the longitudinal change in teenage educational expectations for application to university and of being admitted if applied cannot be known. Further, all of the above studies were based on multiple regression designs which assume that the observed variables are measured without error (Jaccard \& Wan, 1995). All unobserved error, including error from method variance, is clustered in a single term and it is assumed that the observed repeated measures of expectations remain identical over time. These assumptions remain untested. Further, the above studies opted either for the repeated measures of the pupils' reported probability of applying to university or for the reported probability to be admitted if apply, which was nested within the first, but not both. However, both measures are likely to represent two related dimensions of the same underlying construct. Failing to include both in a longitudinal design may leave out an important dimension in a measure of young people's expectation to attend university. In addition, none of the above approaches to studying longitudinal change allows for studying indirect as well as direct longitudinal effects of prior expectations on later expectations. Nor, can they test assumptions about longitudinal or cross-group equivalence (invariance) of the observed measures of adolescent expectations.

\section{The Longitudinal Model of Adolescent Expectations in the Present Study}

The longitudinal model of the present analysis studies change in adolescent expectations between ages 14 (year 9) to 16 (year 11) across groups of white, Indian, Pakistani, Bangladeshi and Black Caribbean young people, stratified according to their mothers' ethnic group. A major focus of the study is to assess whether maternal ethnic group membership moderates longitudinal change in pupils' educational expectations to apply to university and be accepted if apply between ages 14 (year 9) to 16 (year 11). The time window of years 9-11 represents a crucial transition in the lives of UK adolescents. Year 11 marks the end of compulsory education in England and the year where the decision to stay on in full-time education (FTE) or enter the job market materialises.

For each of the five groups in the analysis, I treat adolescent expectations as unobserved or latent variables or factors, considered superior to observed (manifest) measures because they minimize measurement error. They are measured by two observed (or manifest) variables which are imperfect measures of their underlying construct and comprise the measurement part of a confirmatory factor analytic (CFA) model. These two indicators represent repeated measures of two LSYPE questions young people at LSYPE waves 1-3 were asked. The first is pupils' reported likelihood to apply to university: "How likely do you think it is that you will ever apply to go to university to do a degree?" which ranged from "very likely", "fairly likely"; "not very likely" and 
"not at all likely". The second is pupils' reported likelihood to be admitted to university if they applied: "How likely do you think it is that if you do apply to go to university you will get in?", which had a similar response range identical to the first question. Both questions were therefore four-point ordinal Likert type questions and were treated as continuous following general practice.

The second part of a CFA model, the structural model, includes the relations among the latent constructs themselves. The CFA model was extended to become a latent variable structural equation model (LV-SEM). The structural model included all hypothesized regression paths among the independent (called exogenous) and the dependent (called endogenous) latent variables. The LV-SEM of the present study appears in Figure 1.

Figure 1. The Autoregressive Model for Adolescent Educational Expectations (YPEX) for Ages 14 (YPEX1), 15 (YPEX2) and 16 (YPEX3) with Identification, Metric, Scalar and Longitudinal Structural Invariance Constraints in Place

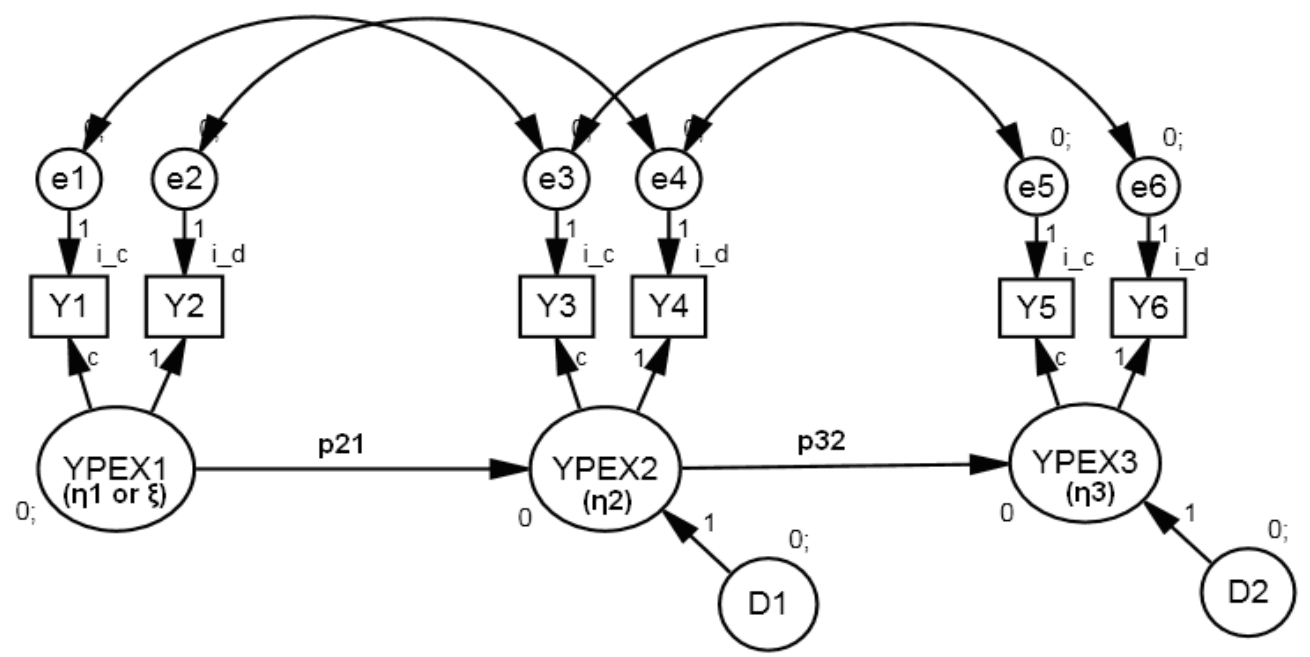

Legend: Y1, Y3, Y5 (reported likelihood to apply to university at ages 14, 15 and 16); Y2, Y4, Y6 (reported likelihood to be admitted if apply at ages 14, 15 and 16, LSYPE waves 1-3).

Each latent factor represents the same construct at three consecutive measurement points (or occasions). For each occasion, there is a CFA model with its own variance-covariance matrix $\mathbf{S}$. The assumption that matrices $\mathbf{S}_{1^{-}} \mathbf{S}_{3}$ are invariant was explicitly tested. Common method variance is extracted by the autocorrelated error structure across the repeated measures. Testable causal hypotheses concern the relations between pupils' expectations at ages 14 (YPEX1), 15 (YPEX2), and 16 (YPEX3) operationalised by regression paths $\mathrm{p}_{21}$, and $\mathrm{p}_{32}$ which describe the dependence of an occasion on its temporally prior one (Bijleveld et al., 1998).

The relations of the indicators to their construct are given by the matrix equations 1-2 below, under the assumptions of normally-distributed, homoscedastic errors with zero means which are uncorrelated with the latent factors $\xi, \eta_{2}, \eta_{3}$; univariate normal and multivariate normal y indicators. 


$$
\begin{aligned}
& \mathrm{y}=\Lambda_{\mathrm{y}} \eta+\varepsilon \\
& \mathrm{x}=\Lambda_{\mathrm{x}} \xi+\delta \\
& \text { which expand and generalise to } \\
& \Sigma=\Lambda \Phi \Lambda^{\prime}+\Theta
\end{aligned}
$$

where $\mathrm{y}$ and $\mathrm{x}$ code the vectors $p$ of the indicators of endogenous and exogenous latent constructs and $\Lambda_{\mathrm{y}}$ and $\Lambda_{\mathrm{x}}$ the $p^{*} p$ matrices of $\mathrm{x}$ and $\mathrm{y}$ loadings. If $m$ codes the number of endogenous and $n$ the number of exogenous factors, $\eta_{2}$ and $\eta_{3}$ represent an $m^{*} m$ and $\xi$ an $n^{*} n$ matrix of the endogenous and exogenous latent factors, while $\varepsilon$ and $\delta$ the $p^{*} p$ matrices of indicator uniquenesses of the $\eta$ and $\xi$ factors. The intercept in equations 1-2 is suppressed because indicator intercepts and means are not included in the analysis of covariance structures in CFA (Brown, 2006). However, the present analysis is based on a means and covariance structures (MACS) framework (Widaman \& Reise, 1997) because a covariance augmented variancecovariance matrix including a vector of indicator means was supplied as input. The structural part of the model in Figure 1 is defined algebraically (Jöreskog, 1969) as:

$$
\eta=\mathrm{B} \eta+\Gamma \xi+\zeta
$$

with $\eta$ and $\xi$ defined as above and $\zeta$ representing unexplained variability (error). $\mathrm{B}$ is an $m * m$ matrix describing the relations among the endogenous latent variables and the $\Gamma$ an $m^{*} n$ matrix representing the relations between any endogenous $(m)$ and exogenous $(n)$ latent variables. In addition, an $\Phi$ covariance $(n * n)$ matrix specifies the covariances among any exogenous $\xi$ and a $\Psi$ covariance $(m * m)$ matrix the covariances between any endogenous $\eta$.

\section{Approaching the Measurement of True (unbiased) Longitudinal Change}

True longitudinal change is defined as change which is due only to the latent means and not biased by other sources of measurement or other error (Chan, 1998). The above autoregressive model controlled for the following sources of potential bias: (a) shared method variance by specifying an autocorrelated error structure; (b) longitudinal noninvariance in the form, loadings and intercepts of the factors $\boldsymbol{\xi}, \boldsymbol{\eta}_{\mathbf{2}}$ and $\boldsymbol{\eta}_{\mathbf{3}}$ by testing for and establishing configural, metric and scalar factorial longitudinal invariance; (c) cross-group noninvariance in the form, loadings and scalar factorial invariance, by testing for and establishing cross-group configural, metric and scalar factorial invariance; (d) bias from sample discrepancy in multigroup analysis. I complete the analysis of longitudinal change by also testing for the stationarity and equilibrium assumptions in the model of pupils' educational expectations. If the regression paths $\mathrm{p}_{21}$ and $\mathrm{p}_{32}$ are statistically equivalent in all ethnic groups, stationarity across time (absence of longitudinal change) is indicated. If the causal system exhibits temporal stability of patterns of covariance and variance, then it is in equilibrium (Dwyer, 1983). Because the above sources of 
bias were controlled for, significant differences across time or across groups in the model of pupils' expectations are much more likely to represent true differences.

\section{Assessing Longitudinal Indirect Effects (mediation)}

The regression paths $\mathrm{p}_{21}$ and $\mathrm{p}_{32}$ shown in Figure 1 represent direct effects. They can be interpreted like partial regression coefficients in multiple regression models. However, occasion 3 in Figure 1 is also affected indirectly by occasion 1 via occasion 2 . Under the present psychometric framework, a total effect can be decomposed into direct $\left(\mathrm{p}_{31}\right)$, and indirect which is calculated as the product of $\mathrm{p}_{21}$ and $\mathrm{p}_{32}\left(\mathrm{p}_{21} \mathrm{p}_{32}\right)$. It shows whether expectations at age 16 (occasion 3 ) are affected directly by immediately prior expectations at age 15 (occasion 2) but also indirectly by even more remote expectations at age 14 (occasion 1). Expressed in the lingo of mediation modelling, the model of Figure 1 tests whether expectations at age 15 mediate between (e.g., explain the association between) early expectations at age 14 and later ones at age 16 .

\section{Assessing Moderation}

In a multiple regression framework, moderation is typically assessed as an interaction term between the moderator (Mo) and the exogenous variable (X) while controlling for the main or "conditional" (Hayes, 2013) effects of the exogenous variables the product of which defines the moderator (see for example, Cooper, 2009). However moderation models with observed variables suffer from major limitations. For example, power to detect moderation is a function of the sample discrepancy that characterises the categories of the moderator and may lead to bogus moderation effects (Aguinis, 1995). Another important interpretation problem is that a statistically significant estimate of the interaction term fails to establish which of the terms in the product (XMo) is the moderator. The problem is compounded if higher-level interaction terms are included in the equation. Instead of interaction terms, the present analysis applies a multigroup approach to test for moderation structural relationships by maternal ethnicity. The advantages of this approach are multi-fold and are summarised nicely by MacKinnon (2008).

\section{Data Source, Treatment and Method of Analysis}

The data source for this study is the Longitudinal Study of Young People in England (LSYPE). The LSYPE is a multipurpose, ongoing large-scale panel study of young people in England commissioned by the Department of Children, Schools and Families (DCSF). The study followed a cohort of 15,770 young people who were in year 9 (between ages 13.5-14.5) mainly in maintained and independent schools in England, in February 2004. Indian, 
Pakistani, Bangladeshi, and Black Caribbean pupils were oversampled by a factor 1.5. There was excellent response rate across LSYPE waves 1-3.

10,633 mothers and the young people structure clustered under the same household survey identification code who had consistently participated across waves 1-3 (full productives) were included in the analysis, stratified by mother's ethnic group. The initial distribution or these pre-selected or trimmed derived samples is shown in Table 1.

Table 1. Sample Sizes of Mothers' Groups

\begin{tabular}{|l|c|}
\hline Groups & N \\
\hline White & 7,578 \\
\hline Indian & 751 \\
\hline Pakistani & 642 \\
\hline Bangladeshi & 484 \\
\hline Black Caribbean & 324 \\
\hline
\end{tabular}

Source: LSYPE waves 1-3 longitudinal File.

Tables 2 and 3 show the frequencies for the repeated measures of the two indicators of the model of pupils' expectations. More than one third of Indian, Pakistani, Bangladeshi and slightly less of Black Caribbean young people expected to go to university and considered successful application for university study "very likely" as compared to one fifth of their white counterparts. Although the proportions of white pupils who regarded a successful university application very likely increased in year 16, the proportions of all the other minority groups increased even more. So, the gaps in educational expectations remained. 
Table 2. Pupil-reported Likelihood to Apply to University (heposs9YP) by Ethnic Group, at LSYPE Waves 1-3

\begin{tabular}{|c|c|c|c|c|c|c|c|c|c|c|c|c|c|c|c|}
\hline & \multicolumn{5}{|c|}{ Wave 1} & \multicolumn{5}{|c|}{ Wave 2} & \multicolumn{5}{|c|}{ Wave 3} \\
\hline Level of likelihood & White & Indian & Pak & Bang & $B C$ & White & Indian & Pak & Bang & $B C$ & White & Indian & Pak & Bang & $B C$ \\
\hline $\begin{array}{l}1.00 \\
\text { Not at all likely }\end{array}$ & 12.0 & 2.2 & 3.2 & 4.1 & 4.1 & 15.4 & 3.0 & 3.6 & 5.1 & 0.4 & 19.9 & 3.3 & 6.2 & 4.6 & 1.5 \\
\hline 2.00 & 18.6 & 4.6 & 8.6 & 11.4 & 11.4 & 20.6 & 5.7 & 9.1 & 9.8 & 6.3 & 18.5 & 3.7 & 6.4 & 9.2 & 5.5 \\
\hline 3.00 & 36.7 & 34.5 & 40.2 & 41.9 & 41.9 & 32.9 & 29.7 & 36.5 & 38.9 & 68.6 & 25.9 & 23.7 & 36.2 & 36.7 & 60.4 \\
\hline $\begin{array}{l}4.00 \\
\text { Very likely }\end{array}$ & 32.7 & 58.8 & 48.1 & 42.6 & 42.6 & 31.1 & 61.6 & 50.7 & 46.1 & 24.7 & 35.7 & 69.3 & 51.2 & 49.6 & 32.7 \\
\hline Total & 7578 & 751 & 642 & 484 & 324 & 7578 & 751 & 642 & 484 & 324 & 7578 & 751 & 642 & 484 & 324 \\
\hline Missing & 4.9 & 3.5 & 7.3 & 9.3 & 9.3 & 4.9 & 2.3 & 6.1 & 7.6 & 16.4 & 4.5 & 2.3 & 4.5 & 5.4 & 15.1 \\
\hline
\end{tabular}

Note: Pak=Pakistani; Bang=Bangladeshi; $\mathrm{BC}=$ Black Caribbean.

Source: Author' estimations.

Table 3. Pupil-reported Likelihoods Being Accepted to University if Applied (hlikeYP), by Ethnic Group, at LSYPE Waves 1-3

\begin{tabular}{|c|c|c|c|c|c|c|c|c|c|c|c|c|c|c|c|}
\hline & \multicolumn{5}{|c|}{ Wave 1} & \multicolumn{5}{|c|}{ Wave 2} & \multicolumn{5}{|c|}{ Wave 3} \\
\hline Level of likelihood & White & Indian & $P a k$ & Bang & $B C$ & White & Indian & Pak & Bang & $B C$ & White & Indian & $P a k$ & Bang & $B C$ \\
\hline $\begin{array}{l}1,00 \\
\text { Not at all likely }\end{array}$ & 1.7 & 0.6 & 0.9 & 0.5 & 0.4 & 2.1 & 0.9 & 1.1 & 0.8 & 0.4 & 1.9 & 0.1 & 0.2 & 0.5 & 1.5 \\
\hline 2,00 & 15.2 & 4.6 & 5.7 & 9.2 & 9.2 & 16.7 & 3.8 & 7.7 & 8.0 & 6.3 & 13.1 & 3.4 & 4.5 & 7.8 & 5.5 \\
\hline 3,00 & 64.2 & 60.7 & 58.7 & 59.2 & 61.0 & 60.3 & 57.9 & 59.0 & 56.5 & 68.6 & 57.9 & 53.6 & 56.1 & 58.3 & 60.4 \\
\hline $\begin{array}{l}4,00 \\
\text { Very likely }\end{array}$ & 19.0 & 34.0 & 34.6 & 31.1 & 29.4 & 20.9 & 37.4 & 32.2 & 34.8 & 24.7 & 27.1 & 42.9 & 39.2 & 33.5 & 32.7 \\
\hline Total & 7578 & 751 & 642 & 484 & 324 & 7578 & 751 & 642 & 484 & 324 & 7578 & 751 & 642 & 484 & 324 \\
\hline Missing & 21.8 & 10.8 & 15.4 & 19.0 & 16.0 & 25.0 & 9.9 & 14.5 & 17.4 & 16.4 & 28.1 & 9.3 & 17.3 & 14.9 & 15.1 \\
\hline
\end{tabular}

Note: Pak=Pakistani; Bang=Bangladeshi; $\mathrm{BC}=$ Black Caribbean.

Source: Author' estimations. 


\section{Minimising Bogus Moderator Effects}

The discrepancy in the original sample sizes of the white and the minority ethnic groups introduces severe bias in the tests of cross-group structural invariance, necessary to detect moderation effects. The chi-square value of the largest group contributes considerably more to the multigroup chi-square in the cross-group invariance test than the other groups in the analysis (Brown, 2006, p. 279). This results in significant chi-square values too often, thus increasing Type I and indicating bogus moderator effects (Chen, 2008). To minimize this bias, I reduced the initial sample of the white group to balance sample discrepancy. Simulation studies suggest a $4 / 1$ ratio as the lower bound of permissible sample size discrepancy (Chen, 2008). A 13.2\% random sample $(n=1,000)$ out of the original 7,578 cases was drawn which reduced the original sample size ratio was from a maximum of 23.4 to 3.1 and a minimum of 10.1 to 1.3 .

All missing values in the white group $(n=1,000)$, Indian $(n=751)$, Pakistani $(n=642)$, Bangladeshi $(n=484)$ and Black Caribbean $(n=324)$ groups were imputed and augmented variance-covariance matrices were constructed on the basis of the pooled (multiply) imputed dataset. The SEM software used in the multigroup analysis was AMOS Graphics 20 (Arbuckle, 2011).

\section{Findings}

\section{Model Fit and Longitudinal Invariance}

Table 4 reports the fit for the model in Figure 1 for all ethnic groups with configural, metric and scalar longitudinal invariance constraints in place. The table reports the chi-square value $\left(\chi^{2}\right)$, as well as the normed fit index (NFI); the relative fit index (RFI); the incremental fit index (IFI); the Tucker-Lewis coefficient (TLI); the comparative fit index (CFI); the root mean square error of approximation (RMSEA); the RMSEA 90\% two-tailed confidence interval as well as the PCLOSE test. As a yardstick, I also note the cut-off points above which indicate very good to excellent fit.

The model of adolescent educational expectations exhibits excellent fit to data. In almost all ethnic groups, the chi-square was statistically nonsignificant, even under the constraints of longitudinal metric invariance and scalar invariance. In the case of Black Caribbean pupils, the chi-square was significant but the rest of the fit indices still indicated excellent fit. Table 5 reports the ML estimates for the factor loadings while Table 8 reports the indicator intercepts for each ethnic group. 
Table 4. Fit to Data of the Model of Pupils' Educational Expectations for each Ethnic Group

\begin{tabular}{|l|c|c|c|c|c|c|c|c|c|c|c|c|c|}
\hline & $\boldsymbol{\chi}^{\mathbf{2}}$ & $\mathbf{d f}$ & $\mathbf{p}$ & $\boldsymbol{C} / \mathbf{d}$ & $\mathbf{N F I}$ & $\mathbf{R F I}$ & $\mathbf{I F I}$ & $\mathbf{T L I}$ & $\mathbf{C F I}$ & RMSEA & LO & HI & PCLOSE \\
\hline White (n=1,000) & 15.9 & 10 & $\mathrm{~ns}$ & 1.586 & 0.996 & 0.993 & 0.998 & 0.998 & 0.998 & 0.024 & 0.000 & 0.046 & 0.979 \\
\hline Indian (n=751) & 6.0 & 9 & $\mathrm{~ns}$ & 0.661 & 0.997 & 0.994 & 1.002 & 1.003 & 1.000 & 0.000 & 0.000 & 0.030 & 1.000 \\
\hline Pakistani (n=642) & 14.6 & 9 & $\mathrm{~ns}$ & 1.621 & 0.989 & 0.982 & 0.996 & 0.993 & 0.996 & 0.031 & 0.000 & 0.059 & 0.850 \\
\hline Bangladeshi (n=487) & 13.5 & 12 & $\mathrm{~ns}$ & 1.123 & 0.987 & 0.984 & 0.999 & 0.998 & 0.999 & 0.016 & 0.000 & 0.05 & 0.947 \\
\hline BCaribbean (n=324) & 20.3 & 10 & 0.0 & 2.031 & 0.969 & 0.954 & 0.984 & 0.976 & 0.984 & 0.056 & 0.019 & 0.092 & 0.338 \\
\hline
\end{tabular}

Note: $\chi^{2}=$ chi-square; $\mathrm{df}=$ degrees of freedom; p=significance; $C / \mathrm{d}=$ ratio of discrepancy to df $(<2.00) ; \mathrm{NFI}=$ normed fit index $(>0.95) ; \mathrm{RFI}=\mathrm{relative}$ fit index $(>0.95)$; $\mathrm{IFI}=$ incremental fit index $(>0.95)$; TLI=Tucker-Lewis index $(>0.95)$; CFI=comparative fit index $(>0.95)$; RMSEA=Root mean square error or approximation $(<0.05)$; LO=lower bound of the RMSEA (0.0); HI=upper bound of the RMSEA $(<0.05)$; PCLOSE=probability that the RMSEA is $\leq 0.05$ in the population $(1,000)$.

Source: Author' estimations.

Table 5. Factor Loadings of the Model of Adolescent Educational Expectations for each Ethnic Group

\begin{tabular}{|c|c|c|c|c|c|c|c|c|c|c|c|c|c|c|c|}
\hline & \multicolumn{3}{|c|}{ White } & \multicolumn{3}{|c|}{ Indian } & \multicolumn{3}{|c|}{ Pakistani } & \multicolumn{3}{|c|}{ Bangladeshi } & \multicolumn{3}{|c|}{ BCaribbean } \\
\hline & $b$ & $S E$ & $\boldsymbol{\beta}$ & $b$ & $S E$ & $\beta$ & $b$ & $S E$ & $\boldsymbol{\beta}$ & $b$ & $S E$ & $\boldsymbol{\beta}$ & $b$ & $S E$ & $\boldsymbol{\beta}$ \\
\hline$\lambda_{11}$ How likely to apply to university w1 & 0.603 & 0.015 & 0.743 & 0.673 & 0.028 & 0.634 & 0.661 & 0.032 & 0.682 & 0.698 & 0.034 & 0.689 & 0.626 & 0.040 & 0.649 \\
\hline$\lambda_{21}$ How likely to get in university if apply w1 & 1.000 & & 0.903 & 1.000 & & 0.850 & 1.000 & & 0.869 & 1.000 & & 0.864 & 1.000 & & 0.828 \\
\hline$\lambda_{12}$ How likely to apply to university w2 & 0.603 & 0.015 & 0.756 & 0.673 & 0.028 & 0.677 & 0.661 & 0.032 & 0.678 & 0.698 & 0.034 & 0.695 & 0.626 & 0.040 & 0.700 \\
\hline$\lambda_{22}$ How likely to get in university if apply w2 & 1.000 & & 0.923 & 1.000 & & 0.871 & 1.000 & & 0.844 & 1.000 & & 0.875 & 1.000 & & 0.823 \\
\hline$\lambda_{13}$ How likely to apply to university w3 & 0.603 & 0.015 & 0.781 & 0.673 & 0.028 & 0.693 & 0.661 & 0.032 & 0.739 & 0.698 & 0.034 & 0.703 & 0.626 & 0.040 & 0.660 \\
\hline$\lambda_{33}$ How likely to get in university if apply w3 & 1.000 & & 0.924 & 1.000 & & 0.918 & 1.000 & & 0.880 & 1.000 & & 0.878 & 1.000 & & 0.888 \\
\hline
\end{tabular}

Note: $\mathrm{b}=$ unstandardized loading; $\beta=$ standardized loading; $\mathrm{SE}=$ standard error. 1.000 under (b) refers to loadings which were fixed to unity for identification purposes.

Like indicators were fixed to unity as a requirement of configural longitudinal and cross-group invariance.

Source: Author' estimations. 
Table 6. ML Estimates for Manifest Indicator Intercepts $(\boldsymbol{\tau})$ for each Ethnic Group

\begin{tabular}{|c|c|c|c|c|c|c|c|c|c|c|}
\hline & \multicolumn{2}{|c|}{ White } & \multicolumn{2}{|c|}{ Indian } & \multicolumn{2}{|c|}{ Pakistani } & \multicolumn{2}{|c|}{ Bangladeshi } & \multicolumn{2}{|c|}{ BCarib } \\
\hline & $\tau$ & $S E$ & $\tau$ & $S E$ & $\tau$ & $S E$ & $\tau$ & $S E$ & $\tau$ & $S E$ \\
\hline$\tau_{1}$ How likely to apply to university w1 & 2.944 & 0.019 & 3.276 & 0.017 & 3.204 & 0.018 & 3.146 & 0.021 & 3.132 & 0.026 \\
\hline$\tau_{2}$ How likely to get in university if apply w1 & 2.980 & 0.027 & 3.513 & 0.020 & 3.307 & 0.022 & 3.238 & 0.026 & 3.216 & 0.035 \\
\hline$\tau_{3}$ How likely to apply to university w2 & 2.944 & 0.019 & 3.276 & 0.017 & 3.204 & 0.018 & 3.146 & 0.021 & 3.132 & 0.026 \\
\hline$\tau_{4}$ How likely to get in university if apply w2 & 2.980 & 0.027 & 3.513 & 0.020 & 3.307 & 0.022 & 3.238 & 0.026 & 3.216 & 0.035 \\
\hline$\tau_{5}$ How likely to apply to university w3 & 2.944 & 0.019 & 3.276 & 0.017 & 3.204 & 0.018 & 3.146 & 0.021 & 3.132 & 0.026 \\
\hline$\tau_{6}$ How likely to get in university if apply w3 & 2.980 & 0.027 & 3.513 & 0.020 & 3.307 & 0.022 & 3.238 & 0.026 & 3.216 & 0.035 \\
\hline
\end{tabular}

Source: Author' estimations.

Table 7. The Structural Part of the Model of Adolescent Educational Expectations across the Five Ethnic Groups

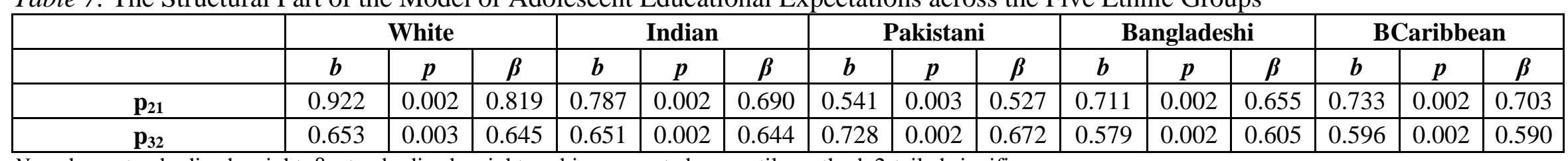

Note: $\mathrm{b}=$ unstandardized weight; $\beta=$ standardized weight; $\mathrm{p}=$ bias-corrected percentile method, 2-tailed significance.

Source: Author' estimations.

Table 8. Standardised ( $\beta$ ) and Unstandardised (b) Direct, Indirect and Total Effect of Expectations at Age 14 on Expectations at Age 16

\begin{tabular}{|c|c|c|c|c|c|c|c|c|c|c|c|c|c|c|c|}
\hline Effect & \multicolumn{3}{|c|}{ White } & \multicolumn{3}{|c|}{ Indian } & \multicolumn{3}{|c|}{ Pakistani } & \multicolumn{3}{|c|}{ Bangladeshi } & \multicolumn{3}{|c|}{ Black Caribbean } \\
\hline & $\boldsymbol{\beta}$ & $b$ & $p$ & $\boldsymbol{\beta}$ & $b$ & $p$ & $\boldsymbol{\beta}$ & $b$ & $p$ & $\boldsymbol{\beta}$ & $b$ & $p$ & $\beta$ & $b$ & $p$ \\
\hline Indirect & 0.528 & 0.602 & $(0.001)$ & 0.444 & 0.513 & $(0.002)$ & 0.354 & 0.394 & $(0.002)$ & 0.396 & 0.412 & $(0.002)$ & 0.415 & 0.467 & $(0.004)$ \\
\hline Direct & 0.223 & 0.254 & $(0.002)$ & 0.108 & 0.124 & $(0.095)$ & 0.100 & 0.111 & $(0.049)$ & 0.110 & 0.114 & $(0.112)$ & 0.160 & 0.168 & $(0.004)$ \\
\hline Total & 0.751 & 0.856 & $(0.003)$ & 0.552 & 0.637 & $(0.002)$ & 0.454 & 0.505 & $(0.002)$ & 0.506 & 0.526 & $(0.002)$ & 0.575 & 0.605 & $(0.002)$ \\
\hline
\end{tabular}

Source: Author' estimations. 
Tables 5 and 6 suggest that all measurement models were very well-fitting and longitudinally consistent. With configural, full metric and full scalar longitudinal invariance achieved, the structural coefficients (paths $\mathrm{p}_{21}$ and $\mathrm{p}_{32}$ ), latent means and latent intercepts can be compared over time. The structural coefficients appear in Table 7. Bias-corrected two-tailed significance (p) is reported based on the percentile method using 1,000-sample Monte Carlo parametric bootstrap.

Estimates of higher magnitude in the time-dependence structural paths $\left(\mathrm{p}_{21}, \mathrm{p}_{32}\right)$ suggest less change (or greater stability) from one occasion to the next. Lower magnitudes suggest higher change (or less stability) from one occasion to the next because each occasion depends less on its prior measurement. Table 7 suggests that the white, Black Caribbean and Pakistani pupils exhibit greater change in their expectations as paths $\mathrm{p}_{21}$ and $\mathrm{p}_{32}$ are quite different in magnitude in these groups. By contrast, Indian and Bangladeshi pupils show greater stability (or less change) in their expectations during the same period.

\section{Direct and Indirect Effects}

As explained above, a significant indirect effect suggests that expectations at age 15 (occasion 2) mediates the influence of expectations at age 14 (occasion 1) to expectations at age 16 (occasion 3). Table 8 shows the decomposition of the total effect of expectations at age 14 on expectations at age 16 and reports the standardised $(\beta)$ and unstandardised (b) estimates for the direct, indirect and total effects. Significance for Table 8 is based on the bootstrapped bias-corrected $\mathrm{p}$ value for each sample of mothers (based on 1,000 bootstrapped samples).

Tables 7 and 8 suggest that expectations at ages 15 and 16 are primarily driven by their directly prior expectations at ages 14 and 15. In all South Asian groups however, prior expectations at age 14 have an insignificant direct influence on expectations at age 16 (the exception to this are the white and the Black Caribbean pupils). Across all groups however, expectations at age 14 exert a very significant indirect effect on expectations at age 16 over and above the direct effects of immediately prior expectations at age 15. The largest magnitude of this indirect effect is found in the white pupils and the smallest in the Pakistani pupils. This suggests that adolescent expectations at age 16 are shaped by both direct and indirect influences from prior expectations at ages 14 and 15. I place these effects in proper context below when I estimate the differences in the latent means and intercepts in expectations.

\section{Do Adolescent Educational Expectations change over Ages 14-16?}

Table 9 presents the results of longitudinal structural invariance for every minority ethnic group. The null hypothesis of longitudinal structural invariance $\left(\mathrm{H}_{0}: \mathrm{p}_{21}=\mathrm{p}_{32}\right)$ is tested in the second row. The decision to reject $(\mathrm{R})$ or not reject 
(NR) the null hypothesis of longitudinal structural invariance is reported in the last column.

Based on the information suggested by Table 9, the null hypothesis of structural invariance in the model parameters could be rejected only in the case of white and Pakistani pupils. Change in expectations between ages 14 to 16 and between 15 to16 was significantly different in the two groups but for different reasons. White pupils' expectations tended to become less stable between ages 15 to 16 but the opposite was the case in the Pakistani group where expectations became more stable (Table 11).

\section{Are Cross-group Differences in Longitudinal Change Moderated by Maternal Ethnicity?}

Moderation by maternal ethnicity is indicated if the dependence paths $\mathrm{p}_{21}$, and $\mathrm{p}_{32}$, are noninvariant across groups. A number of $\mathrm{c}=\left[k^{*}(k-1) / 2\right]$ pairwise comparisons were conducted, where $k$ represented the number of groups in the analysis. Because each group was sequentially compared to all others, there was a higher likelihood of getting a result that would be significant at $\alpha=0.05$ level purely by chance, thus increasing Type I error. A Bonferroni correction adjusted for the $\alpha$ level which was decreased from 0.05 to 0.0125 beyond which the hypothesis of equality between two structural parameters was rejected.

I first conducted an omnibus test of cross-group structural invariance, testing the hypothesis that all $\mathrm{p}_{21}$ paths $\left(\mathrm{H}_{o}: \mathrm{p}_{21 k}=\mathrm{p}_{21}\right)$ and all $\mathrm{p}_{32}$ paths $\left(\mathrm{H}_{o}\right.$ : $\mathrm{p}_{32 k}=\mathrm{p}_{32}$ ) where $k=$ group membership, were cross-group invariant. If the null hypothesis could not be rejected, separate pairwise tests were not necessary because structural estimates were statistically equivalent across groups. If it was rejected, systematic pairwise tests were conducted to identify the source of structural cross-group noninvariance. The hypothesis that paths $\mathrm{p}_{21}$ in each pair of groups are invariant is tested first, followed by the hypothesis that both paths, $\mathrm{p}_{21}$ and $\mathrm{p}_{32}$ are cross-group invariant. In each test, the chi-square difference $\left(\Delta \chi^{2}\right)$ represents the difference between the structurally unconstrained model (denoted as "final scalar") and the two constrained models. Table 10 reports both the omnibus and pairwise tests across white (W), Indian (I), Pakistani (P), Bangladeshi (B) and Black Caribbean (BC) groups. Moderation was assessed on the basis of the significance (p) of the chisquare difference test $\left(\Delta \chi^{2}\right)$ adjusted by the Bonferroni correction.

Pupils' expectations) showed very significant cross-group differences in both path $\mathrm{p}_{21}$, representing change in expectations between ages 14 to 15 $\left(\Delta \chi^{2}=39.4(4) \mathrm{p} \leq 0.00\right)$ and path $\mathrm{p}_{32}$, representing change between ages 15 to 16 $\left(\Delta \chi^{2}=41.9\right.$ (8) $\left.\mathrm{p} \leq 0.00\right)$. The omnibus tests were therefore consistent with the hypothesis that change in expectations was moderated by maternal ethnicity. Some ethnic groups differed most in the change in expectations between ages 14 and 15 while others in the change between ages 15 to 16 . The highest differences between ages 14 to 15 (path $\mathrm{p}_{21}$ ) were found between the white pupils $\left(\mathrm{p}_{21 W}=0.819\right)$ and their Pakistani $\left(\mathrm{p}_{21 P}=0.527 ; \Delta \chi^{2}=38.9(1), \mathrm{p} \leq 0.00\right)$ and 
Bangladeshi $\left(\mathrm{p}_{211}=0.655 ; \Delta \chi^{2}=7.4(1), \mathrm{p} \leq 0.00\right)$ peers. Indian young people $\left(\mathrm{p}_{21}=0.690\right)$ also differed significantly from their Pakistani peers $\left(\mathrm{p}_{21 P}=0.527\right.$; $\Delta \chi^{2}=13.4$ (1), $\left.p \leq 0.00\right)$. In turn, Pakistani pupils differed significantly from their Bangladeshi peers $\left(\Delta \chi^{2}=6.0(1), p \leq 0.00\right)$ during the same period.

Significant cross-group differences in expectations between age 15 and 16 (path $\mathrm{p}_{32}$ ) centred mostly on differences between white pupils and their peers in all the other minority groups. Highly significant differences in both paths $\mathrm{p}_{21}$ and $\mathrm{p}_{32}$ were found between white pupils and their Pakistani $\left(\Delta \chi^{2}=39.1\right.$ (2), $\mathrm{p} \leq 0.00)$, Bangladeshi $\left(\Delta \chi^{2}=8.4\right.$ (2), $\left.\mathrm{p} \leq 0.00\right)$, Black Caribbean pupils $\left(\Delta \chi^{2}=5.3\right.$ (2), $\mathrm{p} \leq 0.00)$ but surprisingly, not their Indian $\left(\Delta \chi^{2}=3.7(2), \mathrm{p}=\mathrm{ns}\right)$ peers. Pakistani pupils also differed significantly from their Bangladeshi $\left(\Delta \chi^{2}=8.3(2)\right.$, $\mathrm{p} \leq 0.00)$ and their Black Caribbean $\left(\Delta \chi^{2}=7.6(2), \mathrm{p} \leq 0.00\right)$ peers. The above evidence suggests a complex picture of cross-group differences in the longitudinal change of pupils' educational expectations between ages 14 to 16 . 
Table 9. Tests of Longitudinal Structural Invariance (Stationarity) of Paths $\mathrm{P}_{21}$ and $\mathrm{p}_{32}$ in each Ethnic Group

\begin{tabular}{|c|c|c|c|c|c|c|c|c|c|c|c|}
\hline Hypothesis & $\chi^{2}$ & $d f$ & $p$ & $\Delta \chi^{2}$ & $d f$ & $p$ & CFI & $\triangle C F I$ & RMSEA & $\triangle R M S E A$ & Decision \\
\hline \multicolumn{12}{|c|}{ White } \\
\hline $\mathbf{p}_{21} \neq \mathbf{p}_{32}$ & 15.1 & 9 & 0.089 & - & - & - & 0.998 & - & 0.026 & - & - \\
\hline $\mathbf{p}_{21}=\mathbf{p}_{32}$ & 29.4 & 10 & 0.001 & 14.3 & 1 & 0.00 & 0.995 & -0.003 & 0.044 & 0.018 & $\mathrm{R}$ \\
\hline \multicolumn{12}{|c|}{ Indian } \\
\hline $\mathbf{p}_{21} \neq \mathbf{p}_{32}$ & 2.3 & 7 & $\mathrm{~ns}$ & - & - & - & 1.000 & - & 0.000 & - & - \\
\hline $\mathbf{p}_{21}=\mathbf{p}_{32}$ & 5.1 & 8 & 0.744 & 2.8 & 1 & ns & 1.000 & 0.00 & 0.000 & 0.00 & NR \\
\hline \multicolumn{12}{|c|}{ Pakistani } \\
\hline $\mathbf{p}_{21} \neq \mathbf{p}_{32}$ & 28.1 & 9 & 0.00 & - & - & - & 0.986 & - & 0.031 & - & - \\
\hline $\mathbf{p}_{21}=\mathbf{p}_{32}$ & 34.1 & 10 & 0.00 & 6 & 1 & 0.014 & 0.982 & -0.014 & 0.061 & 0.03 & $\mathrm{R}$ \\
\hline \multicolumn{12}{|c|}{ Bangladeshi } \\
\hline $\mathbf{p}_{21} \neq \mathbf{p}_{32}$ & 11.2 & 10 & $\mathrm{~ns}$ & - & - & - & 0.999 & - & 0.016 & - & - \\
\hline $\mathbf{p}_{21}=\mathbf{p}_{32}$ & 13.2 & 11 & $\mathrm{~ns}$ & 2 & 1 & ns & 0.998 & 0.001 & 0.020 & 0.004 & NR \\
\hline \multicolumn{12}{|c|}{ Black Caribbean } \\
\hline $\mathbf{p}_{21} \neq \mathbf{p}_{32}$ & 24.5 & 10 & 0.006 & - & - & - & 0.978 & - & 0.067 & - & - \\
\hline $\mathbf{p}_{21}=\mathbf{p}_{32}$ & 25.7 & 11 & 0.007 & 1.2 & 1 & ns & 0.977 & 0.001 & 0.064 & -0.003 & NR \\
\hline
\end{tabular}

Note: $\chi^{2}=$ chi-square; $\mathrm{df}=$ degrees of freedom; $\mathrm{p}=$ significance; $\Delta \chi^{2}=$ chi-square difference; $\mathrm{CFI}=$ comparative fit index ( $\left.>0.95\right) ; \Delta \mathrm{CFI}=\mathrm{CFI}$ difference test; RMSEA=Root mean square error or approximation $(<0.05) ; \triangle \mathrm{RMSEA}=\mathrm{RMSEA}$ difference test; $\mathrm{R}=$ reject $\mathrm{H}_{o}$; $\mathrm{NR}=$ fail to reject the $\mathrm{H}_{o}$.

Source: Author' estimations. 
Table 10. Cross-Group Comparison of the Structural Estimates of the Model of Pupils' Expectations between Ages 14-16

\begin{tabular}{|c|c|c|c|c|c|c|c|c|c|c|c|}
\hline Hypothesis & $\chi^{2}$ & df & $\mathbf{p}$ & $\Delta \chi^{2}$ & df & $\alpha$ & CFI & $\Delta \mathrm{CFI}$ & RMSEA & DRMSEA & Decision \\
\hline Final scalar $^{1}$ & 177.7 & 53 & 0.0 & - & - & - & 0.985 & - & 0.027 & - & \\
\hline $\mathbf{p}_{21 \mathrm{k}}=\mathbf{p}_{21}$ & 217.3 & 57 & 0.0 & 39.4 & 4 & 0.00 & 0.981 & -0.014 & 0.030 & 0.003 & $\mathrm{R}$ \\
\hline$p_{32 k}=p_{32}$ & 219.8 & 61 & 0.0 & 41.9 & 8 & 0.00 & 0.981 & 0.000 & 0.029 & -0.001 & $\mathrm{R}$ \\
\hline $\mathbf{p}_{21 \mathrm{~W}} \neq \mathbf{p}_{21 \mathrm{I}}$ & 19.7 & 16 & $\mathrm{~ns}$ & - & - & - & 0.999 & - & 0.011 & - & \\
\hline $\mathbf{p}_{21 \mathrm{~W}}=\mathbf{p}_{21 \mathrm{I}}$ & 23.3 & 17 & $\mathrm{~ns}$ & 3.6 & 1 & 0.06 & 0.999 & 0.000 & 0.015 & 0.004 & NR \\
\hline$p_{32 W}=p_{32 I}$ & 23.4 & 18 & $\mathrm{~ns}$ & 3.7 & 2 & ns & 0.999 & 0.000 & 0.013 & -0.003 & NR \\
\hline $\mathbf{p}_{21 \mathrm{~W}} \neq \mathbf{p}_{21 \mathrm{P}}$ & 125.7 & 19 & 0.0 & - & - & - & 0.978 & - & 0.059 & - & \\
\hline $\mathbf{p}_{21 \mathrm{~W}}=\mathbf{p}_{21 \mathrm{P}}$ & 164.6 & 20 & 0.0 & 38.9 & 1 & 0.00 & 0.971 & -0.007 & 0.066 & -0.007 & $\mathrm{R}$ \\
\hline $\mathbf{p}_{32 \mathrm{~W}}=\mathbf{p}_{32 \mathrm{P}}$ & 164.8 & 21 & 0.0 & 39.1 & 2 & 0.00 & 0.971 & -0.007 & 0.066 & -0.007 & $\mathrm{R}$ \\
\hline $\mathbf{p}_{21 \mathrm{~W}} \neq \mathbf{p}_{21 \mathrm{~B}}$ & 77.3 & 21 & 0.0 & - & - & - & 0.988 & - & 0.043 & - & \\
\hline $\mathbf{p}_{21 \mathrm{~W}}=\mathbf{p}_{21 \mathrm{~B}}$ & 84.6 & 22 & 0.0 & 7.4 & 1 & 0.00 & 0.987 & -0.001 & 0.044 & 0.001 & $\mathrm{R}$ \\
\hline$p_{32 \mathrm{~W}}=p_{32 \mathrm{~B}}$ & 85.6 & 23 & 0.0 & 8.4 & 2 & 0.00 & 0.987 & 0.000 & 0.043 & -0.001 & $\mathrm{R}$ \\
\hline $\mathbf{p}_{21 \mathrm{~W}} \neq \mathbf{p}_{21 \mathrm{BC}}$ & 67.2 & 21 & 0.0 & - & - & - & 0.989 & - & 0.041 & - & \\
\hline$p_{21 W}=p_{21 B C}$ & 72.1 & 22 & 0.0 & 4.9 & 1 & 0.02 & 0.988 & 0.001 & 0.042 & 0.001 & $\mathrm{R}$ \\
\hline $\mathbf{p}_{32 \mathrm{~W}}=\mathbf{p}_{32 \mathrm{BC}}$ & 72.5 & 23 & 0.0 & 5.3 & 2 & 0.00 & 0.988 & 0.000 & 0.040 & -0.002 & $\mathrm{R}$ \\
\hline $\mathbf{p}_{21 \mathrm{I}} \neq \mathbf{p}_{21 \mathrm{P}}$ & 30.5 & 16 & 0.0 & - & - & - & 0.995 & - & 0.026 & - & \\
\hline$p_{21 I}=p_{21 P}$ & 43.9 & 17 & 0.0 & 13.4 & 1 & 0.00 & 0.991 & -0.004 & 0.037 & 0.011 & $\mathrm{R}$ \\
\hline$p_{32 I}=p_{32 P}$ & 44.4 & 18 & 0.0 & 13.9 & 2 & 0.00 & 0.991 & 0.000 & 0.032 & -0.005 & $\mathrm{R}$ \\
\hline $\mathbf{p}_{21 \mathrm{I}} \neq \mathbf{p}_{21 \mathrm{~B}}$ & 13.8 & 18 & $\mathrm{~ns}$ & - & - & - & 1.000 & - & 0.000 & - & \\
\hline $\mathbf{p}_{21 \mathrm{I}}=\mathbf{p}_{21 \mathrm{~B}}$ & 14.8 & 19 & $\mathrm{~ns}$ & 1.0 & 1 & $\mathrm{~ns}$ & 1.000 & 0.000 & 0.000 & 0.000 & NR \\
\hline$p_{32 I}=p_{32 B}$ & 15.5 & 20 & $\mathrm{~ns}$ & 1.7 & 2 & $\mathrm{~ns}$ & 1.000 & 0.000 & 0.000 & 0.000 & NR \\
\hline $\mathbf{p}_{21 \mathrm{I}} \neq \mathrm{p}_{21 \mathrm{BC}}$ & 27.9 & 18 & $\mathrm{~ns}$ & - & - & - & 0.996 & - & 0.023 & - & \\
\hline$p_{21 I}=p_{21 B C}$ & 28.3 & 19 & $\mathrm{~ns}$ & 0.4 & 1 & ns & 0.996 & 0.000 & 0.021 & 0.001 & NR \\
\hline$p_{32 I}=p_{32 B C}$ & 28.5 & 20 & ns & 0.6 & 2 & ns & 0.996 & 0.000 & 0.020 & 0.001 & NR \\
\hline
\end{tabular}




\begin{tabular}{|c|c|c|c|c|c|c|c|c|c|c|c|}
\hline $\mathbf{p}_{21 \mathrm{P}} \neq \mathbf{p}_{21 \mathrm{~B}}$ & 44.5 & 21 & 0.0 & - & - & - & 0.996 & - & 0.032 & - & \\
\hline $\mathbf{p}_{21 \mathrm{P}}=\mathbf{p}_{21 \mathrm{~B}}$ & 50.5 & 22 & 0.0 & 6.0 & 1 & 0.00 & 0.998 & 0.002 & 0.034 & 0.002 & $\mathrm{R}$ \\
\hline $\mathbf{p}_{32 \mathrm{P}}=\mathbf{p}_{32 \mathrm{~B}}$ & 52.8 & 23 & 0.0 & 8.3 & 2 & 0.00 & 0.988 & 0.000 & 0.034 & 0.000 & $\mathrm{R}$ \\
\hline $\mathbf{p}_{21 \mathrm{P}} \neq \mathbf{p}_{21 \mathrm{BC}}$ & 59.1 & 21 & 0.0 & - & - & - & 0.981 & - & 0.043 & - & \\
\hline $\mathbf{p}_{21 \mathrm{P}}=\mathbf{p}_{21 \mathrm{BC}}$ & 65.1 & 22 & 0.0 & 6.0 & 1 & 0.00 & 0.978 & -0.003 & 0.045 & 0.002 & $\mathrm{R}$ \\
\hline$p_{32 \mathrm{P}}=p_{32 \mathrm{BC}}$ & 66.7 & 23 & 0.0 & 7.6 & 2 & 0.00 & 0.978 & -0.003 & 0.045 & 0.002 & $\mathrm{R}$ \\
\hline $\mathbf{p}_{21 \mathrm{~B}} \neq \mathbf{p}_{21 \mathrm{BC}}$ & 38.0 & 23 & 0.0 & - & - & - & 0.991 & - & 0.028 & - & \\
\hline $\mathbf{p}_{21 \mathrm{~B}}=\mathbf{p}_{21 \mathrm{BC}}$ & 38.1 & 24 & 0.0 & 0.1 & 1 & ns & 0.992 & 0.001 & 0.027 & -0.001 & $\mathrm{NR}$ \\
\hline$p_{32 B}=p_{32 B C}$ & 38.1 & 25 & 0.0 & 0.1 & 2 & $\mathrm{~ns}$ & 0.992 & 0.001 & 0.027 & -0.001 & $\mathrm{NR}$ \\
\hline
\end{tabular}

Note: $\chi^{2}=$ chi-square; $\mathrm{df}=$ degrees of freedom; $\mathrm{p}=$ significance; $\Delta \chi^{2}=$ chi-square difference; $\alpha=$ level of significance; CFI=comparative fit index $(>0.95)$; RMSEA=Root mean square error or approximation $(<0.05) ; \Delta \mathrm{CFI}=$ change in $\mathrm{CFI}(\leq-0.01) ; \Delta \mathrm{RMSEA}=$ change in $\mathrm{RMSEA}(\geq 0.016) ; \mathrm{R}=\mathrm{reject} \mathrm{H}_{\mathrm{o}}$; $\mathrm{NR}=$ fail to reject the $\mathrm{H}_{\mathrm{o}}$; $\mathrm{W}=$ white; $\mathrm{I}=$ Indian; $\mathrm{P}=$ Pakistani, $\mathrm{B}=\mathrm{B}$ angladeshi and $\mathrm{BC}=\mathrm{Black}$ Caribbean.

1: "Final scalar" refers to the final multigroup solution with metric and scalar invariance constraints in place, see last row, Table 14. Source: Author' estimations. 


\section{Is Longitudinal Change in Educational Expectations Moderated by Maternal Ethnicity?}

However, we still need to know whether change from one occasion to the next represents stability at a comparatively high, medium or low level of the latent dimension. High stability in low expectations over time tells quite a different story from low stability in high expectations, for example. Similarly, strong indirect effects of low expectations at age 14 on expectations at age 16 have quite different substantive implications from strong indirect effects of high expectations. Change in latent means and intercepts over time offers this required information. Comparison of latent means and intercepts is conditional on achieving both metric and scalar cross-group measurement invariance. The data fully supported these levels of cross-group invariance (tests available from the author on request).

Latent means and intercepts are unknown quantities of unobserved constructs. Sörbom (1974) has shown that we can estimate the difference in latent means and intercepts between the reference and the comparison groups if the measurement models of both groups are constrained to scalar measurement invariance. Thus, latent means and intercepts represent scaled point differences between the latent mean(s) and latent intercept(s) of the reference group and those of the comparison groups. They test the hypothesis of cross-group equality in factor means $\left(\mathrm{H}_{o}: \mu_{\kappa}=\mu\right)$ and factor intercepts $\left(\mathrm{H}_{o}: \kappa_{\kappa}=\kappa\right)$. A Bonferroni correction was implemented to adjust for Type I error, as above.

Table 11 shows the results from the hypothesis tests of equality of latent means and intercepts for the model of pupils' educational expectations. The reference group in each comparison is noted in bold. Differences in latent means of the exogenous factor $\xi\left(\mu_{1}\right)$ are reported first, followed by the differences in factor intercepts of the first endogenous factor $\eta_{2}\left(\kappa_{2}\right)$, whose differences in factor means $\left(\mu_{2}\right)$ are reported next, followed by the differences in factor intercepts $\left(\kappa_{3}\right)$ and factor means $\left(\mu_{3}\right)$ of the second endogenous factor $\eta_{3}$. 
Table 11. Comparison of Factor Means and Intercepts in the Model of Pupils' Educational Expectations across all Ethnic Minority Groups

\begin{tabular}{|c|c|c|c|c|c|c|c|c|c|c|c|c|c|c|c|}
\hline \multirow{2}{*}{ Ethnic group } & \multicolumn{3}{|c|}{$\begin{array}{c}\text { YPEX1 latent means } \\
\mu_{I}\end{array}$} & \multicolumn{3}{|c|}{$\begin{array}{l}\text { YPEX2 latent } \\
\text { intercepts } \kappa_{2}\end{array}$} & \multicolumn{3}{|c|}{$\begin{array}{c}\text { YPEX2 latent means } \\
\mu_{2}\end{array}$} & \multicolumn{3}{|c|}{$\begin{array}{l}\text { YPEX3 latent } \\
\text { intercepts } \kappa_{3}\end{array}$} & \multicolumn{3}{|c|}{$\begin{array}{c}\text { YPEX3 latent means } \\
\mu_{3}\end{array}$} \\
\hline & $\mu_{1}$ & $S E$ & $p$ & $\overline{\kappa_{2}}$ & $\overline{S E}$ & $p$ & $\mu_{2}$ & $S E$ & $p$ & $\overline{\boldsymbol{\kappa}_{3}}$ & $S E$ & $p$ & $\mu_{3}$ & $S E$ & $p$ \\
\hline White $(n=1000)$ & 0.00 & & & 0.00 & & & 0.00 & & & 0.00 & & & 0.00 & & \\
\hline Indian $(n=751)$ & 499 & 0.036 & 0.000 & 0.080 & 0.023 & 0.00 & 0.506 & 0033 & 000 & 0.170 & 0.022 & 0.00 & 0.602 & 34 & 0.00 \\
\hline Pakistani $(n=642)$ & 345 & 0 & 0.000 & 0.045 & 0 & 0.250 & 0 . & 0 & $\overline{0}$ & 0.065 & & 0.01 & 3 & & 00 \\
\hline Bangladeshi (I & 234 & 0 & 0.000 & 0.067 & 0 . & 0.029 & 0.261 & 0. & 0 & 0.090 & & 0.00 & 0.3 & 0 & .00 \\
\hline$\overline{\text { BCaribbea }}$ & 0.263 & 0.050 & 0.000 & -0.064 & 0.039 & 0.300 & 0.160 & 0.047 & 0.00 & 0.139 & 0.037 & 0.00 & 0.281 & 0.050 & 0.00 \\
\hline Indian $(n=751)$ & 0.00 & & & 0.00 & & & 0.00 & & & 0.00 & & & 0.00 & & \\
\hline Pakistani ( & 192 & 0.035 & 0.000 & -0.056 & 0.028 & 0.04 & -0.209 & 0.033 & 0.00 & -0.035 & 0.025 & 0.232 & -0.199 & 0.036 & 0.00 \\
\hline Bangladeshi $(n=484)$ & -0.304 & 0.039 & 0.000 & -0.041 & 0.031 & 0.350 & -0.281 & 0.038 & 0.00 & -0.015 & 0.028 & 0.450 & -0.231 & 0.038 & 0.00 \\
\hline BCaribbean $(n=324)$ & -0.276 & 0.047 & 0.000 & -0161 & 0.039 & 0.000 & -0.384 & 0.045 & 0.00 & 0.030 & 0.037 & 0.321 & -0.262 & 0.048 & 0.00 \\
\hline Pakistani $(n=642)$ & 0.00 & & & 0.00 & & & 0.00 & & & 0.00 & & & 0.00 & & \\
\hline Bangladeshi $(n=484)$ & -0.111 & 0.040 & 0.004 & 0.003 & 0.031 & 0.892 & -0.078 & 0.039 & 0.045 & 0.027 & 0.028 & 0.257 & -0.029 & 0.040 & 0.471 \\
\hline BCaribbean $(n=324)$ & -0.086 & 0.018 & 0.070 & -0.120 & 0.038 & 0.002 & -0.184 & 0.046 & 0.000 & 0.072 & 0.036 & 0.05 & 0.00 & -0.060 & 0.220 \\
\hline & 0.00 & & & 0.00 & & & 0.00 & & & 0.00 & & & 0.00 & & \\
\hline BCaribbean $(n=324)$ & -0.008 & 0.051 & 0.818 & -0.099 & 0.039 & 0.010 & -0.111 & 0.048 & 0.021 & 0.094 & 0.037 & 0.01 & 0.012 & 0.051 & 0.809 \\
\hline
\end{tabular}

Note: YPEX-3; occasions 1-3 in the model of pupils' educational expectations (Figure 1); p=significance; SE=standard error. Reference groups are noted in bold; $\mathrm{n}=$ sample size. 
Table 11 suggests that at age 14, all groups had significant positive differences in their latent means in educational expectations relative to their white peers indicating their significantly higher expectations relative to their white peers. The highest differences were noted in the Indian $\left(\Delta_{\mu I}=0.499, \mathrm{p} \leq\right.$ $0.00)$ pupils, followed by their Pakistani $\left(\Delta_{\mu}=0.345, \mathrm{p} \leq 0.00\right)$, Black Caribbean $\left(\Delta_{\mu B C}=0.263, \mathrm{p} \leq 0.00\right)$ and Bangladeshi $\left(\Delta_{\mu B}=0.234, \mathrm{p} \leq 0.00\right)$ peers. All of these gaps widened at age 15 and even more so at age 16 relative to white pupils. However, the gaps in latent mean differences of minority pupils relative to their white peers widened very differently in each minority group. Based on the latent intercepts for each group at ages 15 and 16, Indian pupils had the highest net gains in expectations, thus maintaining the biggest gaps in latent mean differences in expectations relative to all other groups between ages 14 to 16 . Differences in their expectations increased most dramatically relative to all other groups between ages 15 to 16. Pakistani pupils also held consistent positive gaps in latent mean differences in expectations relative to their white peers. But these gaps hardly changed between ages 14 to 16 (Table 11, columns, $\mu_{1}, \mu_{2}$ and $\mu_{3}$ for Indian and Pakistani pupils). Bangladeshi pupils widened their positive gaps in latent mean differences in expectations between ages 14 to 15 and still more between ages 15 to 16 . Like their Indian peers, they increased their latent mean differences more during ages 15 to 16 . By comparison, Indian pupils widened their positive gaps in expectations relative to their white peers much faster than did Bangladeshi pupils. This is easily confirmed by the nonsignificant negative latent intercepts of Bangledeshi pupils at age $15\left(\Delta_{\kappa}=-0.041, \mathrm{p}=\mathrm{ns}\right)$ and $16\left(\Delta_{\kappa}=-0.015, \mathrm{p}=\mathrm{ns}\right)$.

Black Caribbean pupils were remarkable in being the only group of pupils to start off at age 14 with a positive gap in their latent mean expectations relative to their white peers $\left(\Delta_{\mu B C}=0.260, \mathrm{p} \leq 0.00\right)$; lower their expectations, narrowing this gap considerably at age $15\left(\Delta_{\mu B C}=0.160, \mathrm{p} \leq 0.00\right)$; and more than regain that advantage relative to their white peers by increasing their latent mean differences again at age $16\left(\Delta_{\mu B C}=0.281, \mathrm{p} \leq 0.00\right)$. This peculiar curve was confirmed by their nonsignificant negative latent intercept at age 15 $\left(\triangle_{\kappa B C}=-0.064, \mathrm{p}=\mathrm{ns}\right)$ and their significant positive latent intercept difference at age $16\left(\Delta_{\kappa B C}=0.134, p \leq 0.00\right)$. In terms of the rate of increase in their latent mean expectations, Black Caribbean pupils caught up with their Pakistani and Bangladeshi peers at age 16 but still lagged behind their Indian peers. This was also confirmed by the Black Caribbean latent intercept differences when those two groups were the reference groups (see Table 11, columns $\kappa_{2}$ and $\kappa_{3}$, last six rows). The above evidence is entirely consistent with the observed cross-group noninvariance of the paths $\mathrm{p}_{21}$ and $\mathrm{p}_{32}$ in the model of educational expectations discussed above.

We can now interpret the observed cross-group noninvariance in paths $p_{21}$ and $\mathrm{p}_{32}$ in terms of the underlying levels of expectations. Cross-group structural non-invariance existed because Indian pupils increased their expectations faster than any other group between ages 14 to 16. Pakistani pupils were significantly different from their Indian peers because Pakistani pupils' expectations remained much more stable (but considerably lower) than those of their Indian 
peers. Bangladeshi pupils were different because although their expectations increased over time, the gaps between them and their other South-Asian peers varied. Finally Black Caribbean pupils were different in that no other group showed a slump in expectations from ages 14 to 15 and a fast recovery from ages 15 to 16 relative to their white peers.

The analysis of longitudinal change in pupils' educational expectations was completed by examining whether the above cross-group structural noninvariance in paths $\mathrm{p}_{21}$ and $\mathrm{p}_{32}$ also meant that the model of pupils' expectations across ethnic groups was in equilibrium (test provided from the author on request). Bringing together the evidence suggests that the causal system of pupils' educational expectations was neither in equilibrium nor stationary for the white and Pakistani pupils. It was stationary but not in equilibrium for their Indian peers, while it was both stationary and in equilibrium for their Bangladeshi and Black Caribbean peers. There are quite important substantive implications regarding pupils' expectations based on the above analysis.

The evidence suggests that expectations for the white, Indian and Pakistani pupils are still developing, while they have reached equilibrium for their Bangladeshi and Black Caribbean peers. This means that for white, Indian and Pakistani pupils, expectations at age 15 are influenced by expectations at age 14 as much as expectations at age 16 are influenced by expectations at age 15 . Their attitudes towards applying to university and of being accepted if apply have not reached stability across time, however. For the white pupils this seems to occur across ages 14-16, while for the Indian pupils mostly between ages 14 to 15 and the Pakistani pupils between ages 15 and 16 .

\section{Discussion and Conclusions}

This paper addressed two questions: First whether pupils' educational expectations changed significantly over the time window between ages 14 to 16. Second, whether this change was moderated by maternal ethnicity. This analysis subjected the measurement assumptions required for such comparisons to rigorous tests and therefore observed change in the structural estimates of the model of pupil's educational expectations was more likely to be true change. This analysis also controlled against bogus moderator effects by reducing the likelihood of biased group chi-square resulting from very discrepant sample sizes as well as applying a Bonferonni correction of the significance level of the chi-square difference tests.

The analysis showed that there were significant cross-group differences in the change of young people's educational expectations over time. Expectations increased over time most dramatically in the Indian pupils relative to all other groups, while they remained consistently the lowest among white pupils. Another significant finding was that earlier expectations determine later expectations for all groups. Most importantly, earlier expectations impact on later expectations both directly and indirectly. While the direct effect of early expectations at age 14 on later expectations at age 16 wanes with time, the 
indirect effect of expectations at age 14 on expectations at age 16 remains very strong and significant. This means that information related to a pupils' decision to apply to university or hope that he/she will get in if they apply obtained at age 15 will force expectations to change more after that point in time. Fumagalli's (2012) suggestion that pupils' expectations tended to change immediately after GCSE results were known at age 15 seems therefore to gain some support. However, the present analysis also showed that information gained much earlier at age 14 also exerts important indirect effects on expectations at age 16 .

But the major finding of this study was that maternal ethnicity moderated differently not only the change in expectations from age 14 to 16 but also the change in the latent mean levels of pupils' expectations. Maternal ethnicity seems to moderate the extent to which the causal system of pupils' educational expectations between ages 14 to 16 has reached equilibrium or alternately, is still in the process of development. Maternal ethnicity moderates longitudinal change in expectations in at least four ways: (a) by affecting the rate of change between ages 14 to 15 and 15 to 16 ; (b) by affecting the extent to which prior expectations exert a direct net impact on later expectations; (c) by affecting the strength of indirect influences of prior expectations on later expectations; and (d) by affecting the mean levels of pupils' expectations related to university study. The study contributes to past UK research on pupils' educational expectations because it showed how moderation by maternal ethnicity impacts on pupils expectations for university study maintaining gaps in expectations.

It should be finally noted that the data on which this study was based were observational and therefore no causal conclusions can be drawn. Further, the model presented and analysed in this study included prior expectations at age 14 as the sole predictor of adolescent educational expectations at age 16 to the exclusion of other background predictors, mediators or moderators. It did this because it focused strictly on the estimation of longitudinal change in expectations between ages 14 to 16 and of their moderation by maternal ethnicity. It is clear that the model of educational expectations as presented here should be thought of as only part of a much more complex model of the development of educational expectations (Flouri \& Hawkes, 2008; Goyette \& Xie, 1999; Kaplan, Liu \& Kaplan, 2001; Thompson et al., 1988). However, recent research that has systematically controlled for a number of prior influences on adolescent educational expectations has shown that prior expectations are by far the strongest predictor of later expectations across all UK minority groups (Tzanakis, 2014). As a result, policy interventions targeting early expectations and enriched by qualitative in-depth information will help raise expectations more effectively. 


\section{References}

Aguinis, H. (1995). Statistical power problems with moderated multiple regression in management research. Journal of Management Research, 21, 1141-1158.

Anders, J., \& Micklewright, J. (2013). Teenagers' expectations of applying to university: how do they change? London: Institute of Education.

Arbuckle, J. L. (2011). IBM-SPSS Amos20 User's Guide: IBM Corporation.

Bijleveld, C. C. J. H., van der Kamp, L. J. T., Mooijaart, A., van der Kloot, W. A., van der Leeden, R. \& van der Burg, E. (1998). Longitudinal data analysis: Designs, models and methods. London: Sage Publications.

Brown, T. (2006). Confirmatory factor analysis for applied research. New York: The Guildford Press.

Chan, D. (1998). The conceptualization and analysis of change over time: An integrative approach incorporating longitudinal mean and covariance structures analysis (LMACS) and multiple indicator latent growth modeling (MLGM). Organizational Research Methods, 1(4), 421-483.

Chen, F. F. (2008). What happens if we compare chopsticks with forks? The impact of making inappropriate comparisons in cross-cultural research. Journal of Personality and Social Psychology, 95(5), 1005-1018.

Cooper, M. A. (2009). Dreams deferred? The relationship between early and later postsecondary educational aspirations among racial/ethnic groups. Educational Policy, 23(4), 615-650.

Dwyer, J. H. (1983). Statistical models for the social and behavioral sciences. New York: Oxford University Press.

Flouri, E., \& Hawkes, D. (2008). Ambitious mothers-successful daughters: mothers' early expectations for children's education and children's earnings and sense of control in adult life. British Journal of Educational Psychology, 78, 411-433.

Fumagalli, E. (2012). Great expectations. Channels and barriers to university education. Retrieved from http://bit.ly/1JC631v.

Gottfredson, L. S. (1996). Gottfredson's theory of circumscription and compromise. In B. D. \& L. Brooks (Eds), Career Choice and Development. San Francisco, CA: Jossey-Bass.

Goyette, K., \& Xie, Y. (1999). Educational Expectations of Asian American Youths: Determinants and Ethnic Differences. Sociology of Education, 72(1), 22-36.

Goyette, K. A. (2008). College for some to college for all: social background, occupational expectations, and educational expectations over time. Social Sicience Research, 37, 461-484.

Hayes, A. F. (2013). Introduction to mediation, moderation and conditional process analysis: a regression-based approach. New York: The Guilford Press.

Jaccard, J., \& Wan, C. K. (1995). Measurement error in the analysis of interaction effects between continuous predictors using multiple regression: multiple indicator and structural equation approaches. Psychological Bulletin, 117, 433465.

Jerrim, J. (2011). Disadvantaged children's "low" educational expectations: are the US and UK really so different to other industrialized nations? Department of Quantitative Social Science: Institute of Education, University of London.

Jöreskog, K. G. (1969). A general approach to confirmatory maximum likelihood factor analysis. Psychometrika, 34, 183-202.

Jose, E. P. (2013). Doing statistical mediation and moderation. New York: The Guilford Press. 
Kaplan, D. S., Liu, X., \& Kaplan, H. B. (2001). Influence of parents' self-feelings and expectations on children's academic performance. The Journal of Educational Research, 94(6), 360-370.

Lee, J. O., Hill, K. G., \& Hawkins, J. D. (2012). The role of educational aspirations and expectations in the discontinuity of intergenerational low-income status. Social Work Research, 36(2), 141-151.

MacKinnon, D. P. (2008). Introduction to Statistical Mediation Analysis. New York: Taylor and Francis.

Quaglia, R. J., \& Cobb, C. D. (1996). Toward a theory of stuident aspirations. Journal of Research in Rural Education, 12(3), 127-132.

Rutter, M., \& Tienda, M. (2005b). Deciphering ethnicity: reflections on research opportunities. In M. Rutter \& M. Tienda (Eds), Ethnicity and Causal Mechanisms. Cambridge: Cambridge University Press.

Sewell, W. H., Hauser, R. M., \& Wolf, W. C. (1980). Sex, Schooling, and Occupational Status. The American Journal of Sociology, 86(3), 551-583.

Sörbom, D. (1974). A general method for studying differences in factor means and factor structure between groups. British Journal of Mathematical and Statistical Psychology, 27, 229-239.

Strand, S. (2014). Ethnicity, gender, social class and achievement gaps at age 16: Intersectionality and "Getting it" for the white working class. Research Papers in Education, 29(2), 131-171.

Strand, S., \& Winston, J. (2008). Educational aspirations in inner city schools. University of Warwick institutional repository. Retrieved from http://bit.ly/1OBwSHe.

Thompson, M. S., Alexander, K. L., \& Entwisle, D. R. (1988). Household composition, parental expectations and school achievement. Social Forces, 67(2), 424-451.

Tzanakis, M. (2014). An exploration of ethnic differences of the influences of home and school on the development of young people's educational expectations for university study between ages 14 to 16 (Unpublished Doctoral Thesis). Institute of Education, University of London, London.

Widaman, K. F., \& Reise, S. P. (1997). Exploring the measurement invariance of psychological instruments: Applications in the substance use domain. The science of Prevention: Methodological advances from alcohol and substance abuse research (pp. 281-324). Texas: University of Houston. Retrieved from http://bit.ly/1TVUNnW.

Woelfel, J., \& Haller, A. O. (1971). Significant others, the self-reflexive act and the attitude formation process. American Sociological Review, 36(1), 74-87. 